\title{
Desain Modifikasi Struktur Gedung Apartemen One East Surabaya Menggunakan Struktur Flat Slab dengan Penambahan Shear Wall
}

\author{
Firly Ayu Agus Dian, I Gusti Putu Raka, Tavio \\ Departemen Teknik Sipil, Fakultas Teknik Sipil, Lingkungan dan Kebumian \\ Institut Teknologi Sepuluh Nopember \\ e-mail: tavio@ce.its.ac.id; raka@ce.its.ac.id
}

\begin{abstract}
Abstrak-Gedung Apartemen One East di Surabaya merupakan gedung yang difungsikan sebagai hunian vertikal yang dibangun di kawasan perumahan. Apartemen One East sendiri merupakan gedung dengan struktur 31 lantai yang memiliki tipe tipikal sehingga mulai dari lantai 4 ke atas mempunyai konfigurasi denah yang sama. Pada Desain struktur gedung apartement One East ini akan di desain ulang dengan menggunakan struktur Flat Slab. Rangka utama akan didesain sebagai Sistem Rangka Gedung dan dinding struktur didesain sebagai dinding struktur beton khusus. Berdasarkan hasil analisa yang telah dilakukan didapatkan ringkasan bahwa rangka utama gedung mampu menahan beban lateral arah $\mathrm{X}$ dan $Y$ yang masing-masing arah sebesar $8,41 \%$ dan $4,85 \%$ sehingga syarat Sistem Rangka Gedung terpenuhi. Analisa harga terhadap perbedaan tebal pelat dilakukan untuk mengetahui efektivitas pemilihan tebal pelat yang efisien dan ekonomis. Dari hasil analisa tersebut didapatkan bahwa biaya pembuatan Option 1 (t pelat $=350 \mathrm{~mm}, \mathrm{t}$ drop panel $=100 \mathrm{~mm}$ ) menghasilkan harga pembuatan sebesar $R p 74.553 .887$ dan biaya pembuatan Option 2 (t pelat $=\mathbf{2 5 0} \mathrm{mm}, \mathrm{t}$ drop panel $=\mathbf{2 0 0}$ mm) menghasilkan harga pembuatan sebesar Rp66.499.595. Sehingga dalam pembuatannya Option 2 dapat menghemat biaya pembuatan pelat sebesar $10,803 \%$.
\end{abstract}

Kata Kunci-Flat Slab, Beton bertulang, Shear Wall, Drop Panel, Coloumn Capital.

\section{PENDAHULUAN}

$\mathrm{B}$ ERKEMBANGNYA infrastruktur yang semakin pesat memacu peningkatan laju pertumbuhan urbanisasi dari desa ke kota. Menurut data Dinas Pendaftaran Penduduk dan Pencatatan Sipil kota Surabaya, pada tahun 2009 angka urbanisasi penduduk dari luar kota ke wilayah Surabaya yakni sebesar 50,995 jiwa, sedangkan pada tahun 2014 mengalami peningkatan yang cukup signifikan yakni sebesar 67,416 jiwa. Tingginya tingkat urbanisasi masyarakat ke wilayah Surabaya mengakibatkan adanya peningkatan kebutuhan hunian. Semakin minim lahan yang tersedia di Surabaya mendorong adanya pembangunan hunian ke arah vertikal. Salah satu upaya pemerintah untuk menciptakan hunian yang layak di wilayah Surabaya adalah dengan memaksimalkan pembangunan hunian ke arah vertikal seperti hunian apartemen.

Meningkatnya permintaan terhadap kebutuhan hunian vertikal membuat pengembang/investor berlomba dalam menciptakan hunian vertikal yang ekonomis, sehingga mengesampingkan faktor kenyamanan hunian seperti tinggi ruang bebas yang menjadi salah satu faktor kenyamanan penghuni apartemen.

Struktur gedung pada umumnya memiliki komponenkomponen penyusun yang menyatu seperti pelat, balok dan kolom. Namun saat ini penggunaan sistem struktur konvensional balok - kolom dinilai kurang efektif diaplikasikan pada gedung apartemen karena memiliki tinggi ruang bebas yang rendah. Melihat kondisi yang harus dipertimbangkan seperti yang dijelaskan sebelumnya, maka diperlukan adanya alternatif sistem struktur yang memiliki tinggi ruang bebas yang besar, namun tetap bernilai ekonomis. Salah satu alternatif sistem struktur yang dapat meningkatkan tinggi ruang bebas gedung adalah sistem struktur Flat Slab.

Pada studi ini akan direncanakan alternatif sistem struktur konstruksi Flat Slab pada gedung apartemen One East Surabaya dengan menggunakan beberapa alternatif perkuatan untuk menunjang sistem struktur Flat Slab. Alternatif konstruksi perkuatan yang pertama adalah dengan adanya Drop Panel sebagai penahan geser struktur, dan alternatif konstruksi perkuatan yang kedua adalah dengan adanya Coloumn Capital sebagai penahan geser pada bagian kritis daerah kolom. Dari kedua alternative konstruksi tersebut akan dibandingkan efisiensi tinggi ruang bebas yang didapatkan pada pemgedung apartemen One East Surabaya.

\section{TINJAUAN PUSTAKA}

Flat Slab merupakan sistem struktur dengan pelat beton bertulang yang diperkuat dua arah langsung ditunjang oleh kolom tanpa adanya balok[1]. Sistem flat slab merupakan sistem yang sangat simpel untuk metode konstruksi dan untuk bangunan dengan tinggi yang minimum. Analisis dinamik dari flat slab dan pelat dua arah konvensioanal untuk analisis seismik dengan mempertimbangkan perbedaan area seismik yang sangat mempengaruhi[2].

Tebal pelat dan kebutuhan tulangan untuk sistem flat slab dihitung berdasarkan nilai-nilai ultimit gaya dalam hasil analisis struktur. Setelah itu, tulangan yang akan dirancang harus kuat untuk menahan besarnya momen positif dan momen negatif, sehingga terdapat dua bagian perancangan dalam hal ini, yaitu perancangan tulangan momen positif dan tulangan momen negatif. 


\section{METODOLOGI}

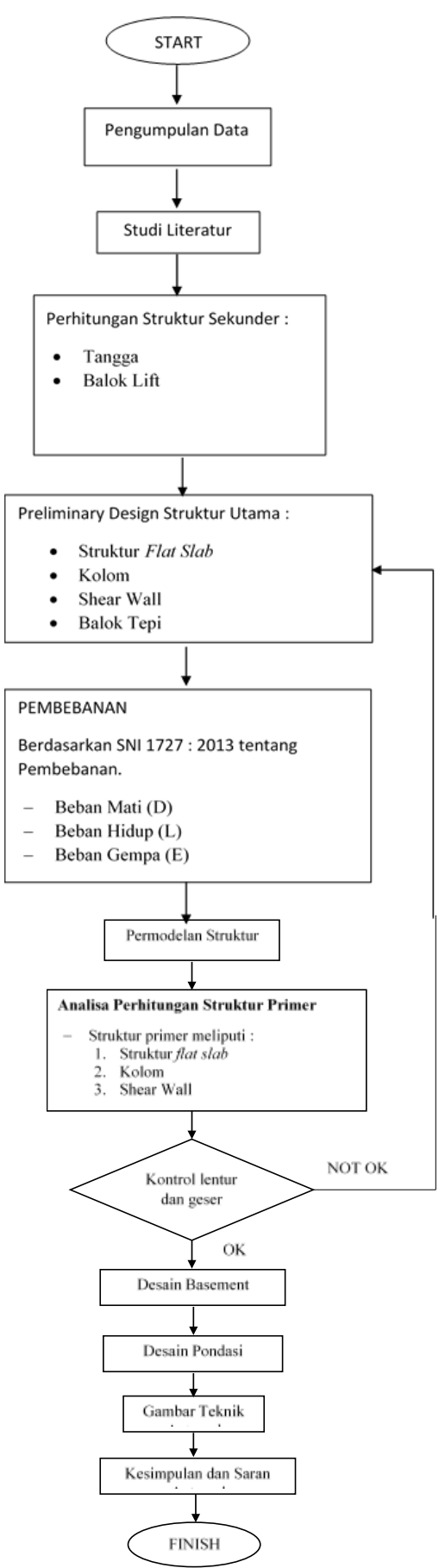

Gambar 1. Bagan Alur Metodologi

\section{Data Gedung}

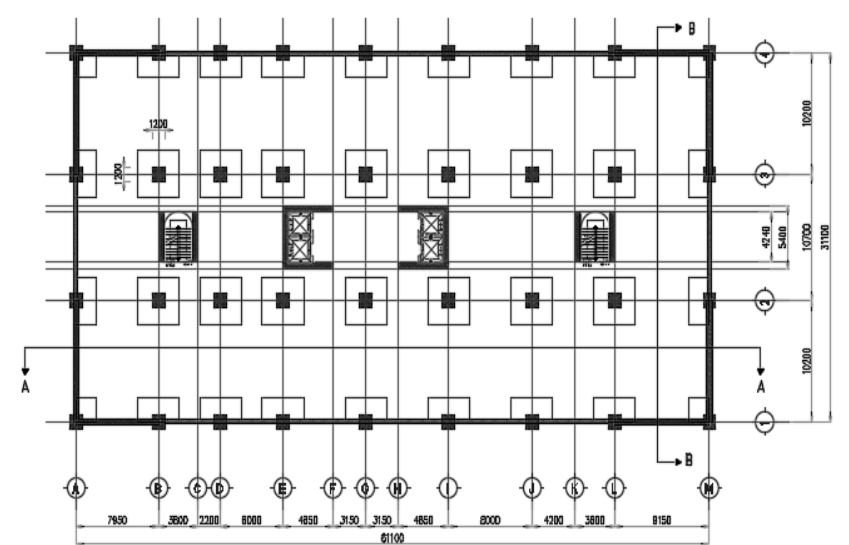

Gambar 2. Denah Gedung

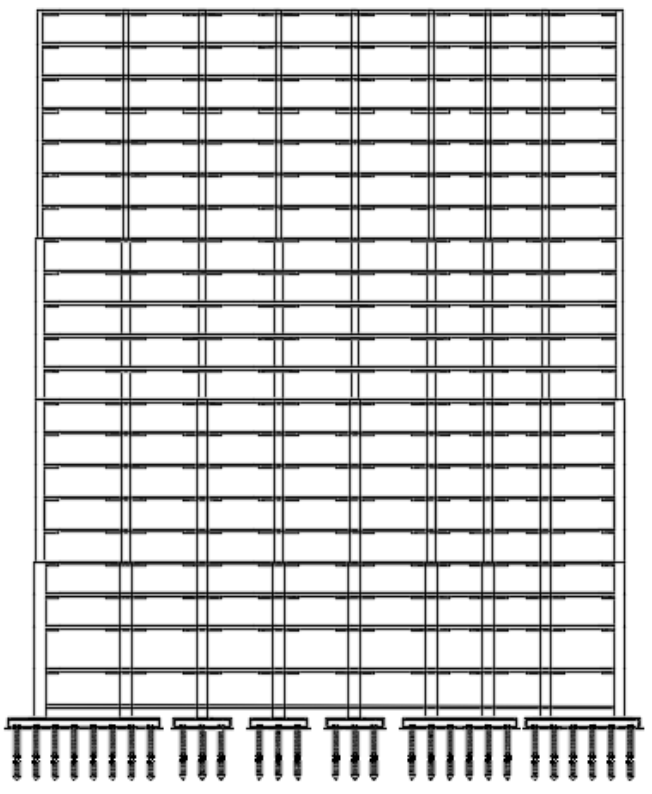

Gambar 3 Potongan Memanjang Apartement One East Surabaya

Desain Gedung Apartemen One East menggunakan sistem Flat Slab. Data bangunan yang akan digunakan dalam pengerjaan Studi yaitu :

- Tipe Bangunan : : Gedung Apartemen

- Lokasi

- Ketinggian Lantai

O Basement

: Surabaya

$: 4 \mathrm{~m}$

: $4,5 \mathrm{~m}$

o Lantai $1-19$ : 3,4 m

- Luas Lantai $\quad: \pm 1842,586 \mathrm{~m}^{2}$

- Tinggi Total Bangunan: $\pm 69,7 \mathrm{~m}$

- Mutu Beton (f'c) : $40 \mathrm{MPa}$

- Mutu Baja (fy) : $400 \mathrm{MPa}$

- Data Tanah : Terlampir

- Data Gambar : : Terlampir

\section{ANALISA PERHITUNGAN}

\section{A. Permodelan Struktur}

Dalam Desain gedung bertingkat perlu dilakukan adanya Desain pembebanan gravitasi maupun pembebanan gempa. Program bantu ETABS 2016 akan membantu dalam cek serta kontrol perhitungan struktur sesuai persyaratan yang telah ditetapkan dalam SNI 1726 : 2012.

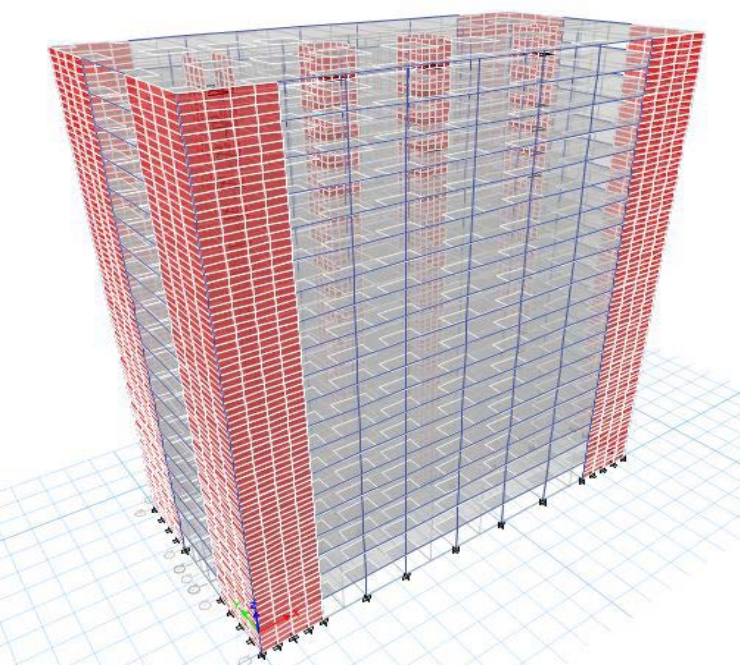

Gambar 4. Permodelan Struktur pada ETABS 


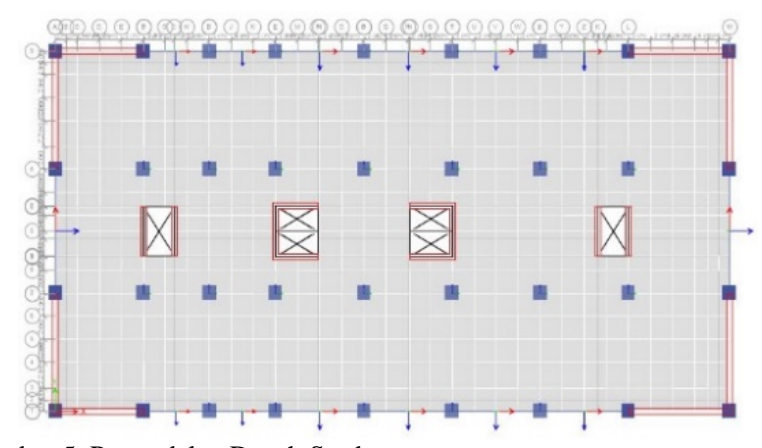

Gambar 5. Permodelan Denah Struktur

\section{B. Pembebanan Gravitasi}

Pembebanan Gravitasi berupa beban mati dan beban hidup yang bekerja pada gedung. Beban mati dan hidup yang dipehitungkan berupa beban mati berdasarkan PPIUG 1983 dan beban hidup berdasarkan SNI 1727:2013[3], [4].

Dari analisa pembebanan Gravitasi pada gedung Apartemen One East yang telah dilakukan didapatkan total beban secara manual (1D +1L) adalah $53105903,87 \mathbf{~ k g}$.

Didapatkan total beban gravitasi pada ETABS (1D+1L) sebesar $\mathbf{5 1 4 4 5 1 6 2 , 9 0} \mathbf{~ k g}$. Sehingga selisih antara perhitungan manual dengan permodelan ETABS yaitu sebagai berikut :

Tabel 1.

Rekapitulasi Beban Mati dan Beban Hidup

\begin{tabular}{ccc}
\multicolumn{2}{c}{ Rekapitulasi Beban Mati dan Beban Hidup } & \\
\hline \hline Dead Manual (D) & 46201729,98 & $\mathrm{~kg}$ \\
Live Manual (L) & 6904173,89 & $\mathrm{~kg}$ \\
Berat Etabs (D) & 44548168,00 & $\mathrm{~kg}$ \\
Berat Etabs (L) & 6896994,90 & $\mathrm{~kg}$ \\
D+L Etabs & 51445162,90 & $\mathrm{~kg}$ \\
D+L Manual & 53105903,87 & $\mathrm{~kg}$ \\
Selisih & 1660740,97 & $\mathrm{~kg}$ \\
\% Selisih & 3,228 & $\%$ \\
\hline \hline
\end{tabular}

Selisih 3,228\% < 5\%, dengan perhitungan manual. Dengan demikian pemodelan struktur dianggap sesuai.

\section{Pembebanan Gempa}

Pembebanan gempa dengan mengacu pada SNI 1726:2012, yang di dalamnya terdapat ketentuan dan persyaratan perhitungan beban gempa[5].

Berdasarkan pasal 4.1.2 SNI 1726-2012, struktur ini termasuk dalam kategori risiko II (Gedung Apartemen) dengan faktor keutamaan gempa $(\mathrm{Ie})=1$.

Berdasarkan pasal 6.2 SNI 1726-2012, nilai Ss dan Ss ditentukan berdasarkan peta zona gempa pada Gambar 9 dan 10 di SNI 1726-2012. Sehingga didapatkan nilai Ss $=0,663$ dan $\mathrm{S} 1=0,247$.

Berdasarkan pasal 6.3 SNI 1726-2012, parameter percepatan spektral desain, yaitu SDS dan SD1 ditentukan berdasarkan rumus di bawah ini.

$$
\begin{aligned}
& \mathrm{S}_{\mathrm{DS}}=\frac{2}{3} \mathrm{~S}_{\mathrm{MS}}=\frac{2}{3} \times 0,91=0,607 \\
& \mathrm{~S}_{\mathrm{D} 1}=\frac{2}{3} \mathrm{~S}_{\mathrm{M} 1}=\frac{2}{3} \mathrm{x} 0,74=0,496
\end{aligned}
$$

Dengan nilai-nilai tersebut, struktur gedung diklasifikasikan sebagai kategori desain seismik kategori D. Untuk kategori desain seismik D, dapat digunakan sistem rangka gedung (SRG) sebagai sistem strukturnya. Dengan sistem rangka gedung dengan dinding geser beton bertulang khusus maka 90\% gaya gempa akan di pikul dinding geser. Parameter sistem struktur untuk arah $\mathrm{x}$ dan y dengan dinding geser beton bertulang khusus adalah $\mathrm{Ro}=6, \Omega_{\mathrm{o}}=2,5$ dan $\mathrm{C}_{\mathrm{d}}=5$.

Berdasarkan analisa program bantu ETABS 2016 didapatkan periode fundamental struktur sebesar 1,528. Sehingga Tc $=1,528$ detik. Berdasarkan kontrol waktu getar alami fundamental nilai Tc berada diantara range Ta minimum dan Ta maksimum yakni :

Ta minimum $<$ Tc $<$ Ta maksimum

$$
1,177<1,528<1,648
$$

Dan nilai koefisien respon seismik (Cs) :

$\mathrm{Cs}=0,044 \times \mathrm{S}_{\mathrm{DS}} \times \mathrm{I}_{\mathrm{e}}=0,044 \times 0,607 \times 1=0,0267 \geq 0,01$

Maka nilai Cs diambil sebesar 0,064.

Gaya geser yang telah didapatkan dari perhitungan di atas akan didistribusikan secara vertikal ke masing-masing lantai sesuai dengan SNI 1726:2012.

$$
\begin{aligned}
& \mathrm{V}=\mathrm{Cs} \times \mathrm{W} \\
& \mathrm{V}=0,064 \times 46617266,33=2983505,045 \mathrm{kgf}
\end{aligned}
$$

Jika kombinasi respons untuk geser dasar ragam (Vt) lebih kecil 85 persen dari geser dasar yang dihitung (V) menggunakan prosedur gaya lateral ekivalen, maka gaya harus dikalikan dengan faktor skala $0,85 \mathrm{~V} / \mathrm{Vt}$ (SNI 1726:2012 Pasal 7.9.4.1). Sehingga didapatkan nilai gaya geser dasar yang telah dikalikan dengan faktor skala adalah sebagai berikut $\mathrm{V}=2983505,045 \mathrm{kgf}$ dan $0,85 \mathrm{~V}=$ 2535979,288 kgf.

\section{Perencanaan Struktur Sekunder}

Struktur sekunder tidak menahan beban secara keseluruhan, namun tetap mengalami tegangan akibat pembebanan yang bekerja secara langsung pada bagian tersebut, maupun perubahan bentuk dari struktur primer.

Analis Perhitungan struktur sekunder yang akan dibahas pada bab ini diantaranya adalah perancangan tangga, balok bordes dan perancangan balok penggangtung lift.

\section{1) Perencanaan Tangga}

Tangga akan didesain dengan meletakan pelat bordes pada setengah tinggi antar lantai dengan denah tangga data desain sebagai berikut :

- Mutu beton (fc') = = $40 \mathrm{MPa}$

- Mutu baja (fy) = $\quad 400 \mathrm{MPa}$

- Tinggi antar lantai $\quad=340 \mathrm{~cm}$

- Panjang bordes $\quad=280 \mathrm{~cm}$

- Lebar bordes = $124 \mathrm{~cm}$

- Lebar injakan = $30 \mathrm{~cm}$

- Tinggi tanjakan $\quad=15 \mathrm{~cm}$

- Lebar tangga $\quad=130 \mathrm{~cm}$

- Tebal pelat tangga (tp) $=15 \mathrm{~cm}$

- Tebal pelat bordes $=15 \mathrm{~cm}$

Tabel 2.

Rekapitulasi Penulangan Tangga

\begin{tabular}{cccc}
\hline \hline \multirow{2}{*}{ Nama Struktur } & \multicolumn{3}{c}{ Tulangan } \\
\cline { 2 - 4 } & Lentur & Susut & Bagi \\
\hline Pelat Tangga & D16-140 & D10-200 & D10 -200 \\
Pelat Bordes & D16-200 & D10-200 & D10 -200 \\
\hline \hline
\end{tabular}

2) Perencanaan Balok Bordes

Desain balok bordes sesuai dengan SNI-2847-2013 pasal 9.5.2.1 tabel 9.5a. Direncanakan balok bordes dengan dimensi $\mathrm{b}=200 \mathrm{~mm}, \mathrm{~h}=300 \mathrm{~mm}$. Berikut adalah hasil rekapitulasi penulangan balok bordes : 
Tabel 3.

Rekapitulasi Penulangan Balok Bordes

\begin{tabular}{ccc}
\hline \hline \multirow{2}{*}{ Nama Struktur } & \multicolumn{2}{c}{ Tulangan } \\
\cline { 2 - 3 } & Lentur & Geser \\
\hline Balok Bordes & D12 & D10 - 100 \\
\hline \hline
\end{tabular}

3) Perencanaan Balok Penggantung Lift

Perencanaan yang dilakukan pada lift ini meliputi balokbalok yang berkaitan dengan mesin lift. Pada bangunan ini digunakan lift penumpang yang diproduksi oleh Hyundai Elevator dengan data-data spesifikasi sebagai berikut :

- Tipe Lift

- Kapasitas

: Passenger Elevator

- Kecepatan

$: 1000 \mathrm{Kg}$

: $105 \mathrm{~m} / \mathrm{min}$

- Dimensi sangkar ( car size )
o Car Wide (CW)
: $1660 \mathrm{~mm}$
o Car Depth (CD)
: $1655 \mathrm{~mm}$
o Opening
: $900 \mathrm{~mm}$

- Dimensi ruang luncur ( Hoistway )

o Hoistway width (HW) : $4200 \mathrm{~mm}$

o Hoistway Depth (HD) : 2130 mm

- Beban reaksi ruang mesin
o R1
: $5450 \mathrm{~kg}$
: $4300 \mathrm{~kg}$

o R2

Balok penggantung lift direncanakan menggunakan profil WF 350 x $175 \times 7 \times 11$, dengan data sebagai berikut :
$\mathrm{W}=49,6 \mathrm{~kg} / \mathrm{m}$
$\mathrm{tw}=7 \mathrm{~mm}$
$\mathrm{Zx}=841 \mathrm{~cm}^{3}$
A $=63,14 \mathrm{~cm}^{2}$
$\mathrm{tf}=11 \mathrm{~mm}$
$\mathrm{Ix}=13600 \mathrm{~cm}^{4}$
$\mathrm{d}=350 \mathrm{~mm}$
$\mathrm{r}=14 \mathrm{~mm}$
Iy $=984 \mathrm{~cm}^{4}$
bf $=175 \mathrm{~mm}$
$\mathrm{h}=300 \mathrm{~mm}$
$\mathrm{Sx}=775 \mathrm{~cm}$

4) Preliminary Design

Perencanaan awal dilakukan menurut peraturan SNI 2847:2013. Preliminary desain yang dilakukan terhadap komponen struktur antara lain balok tepi, balok anak, pelat, shearwall dan kolom. Sebelum melakukan preliminary baiknya dilakukan penentuan data perencanaan dan beban yang akan diterima oleh struktur gedung.

- Pelat

$$
\begin{array}{ll}
\text { o Option } 1 & : 350 \mathrm{~mm} \\
\text { o Option 2 } & : 250 \mathrm{~mm}
\end{array}
$$

- Drop Panel

o Option 1

o Dimensi

: $4000 \times 4000 \mathrm{~mm}$

o Tebal

: $100 \mathrm{~mm}$

o Option 2

o Dimensi

: $4000 \times 4000 \mathrm{~mm}$

o Tebal

: $200 \mathrm{~mm}$

- Dimensi Kolom

o Groundfloor - Lt 3 : 1200 m x 1200 m

o Lantai 4-8 : $1000 \mathrm{~m} \times 1000 \mathrm{~m}$

o Lantai $9-13 \quad: 800 \mathrm{~m} \times 800 \mathrm{~m}$

o Lantai 14 - Atap : $600 \mathrm{~m}$ x $600 \mathrm{~m}$

- Dimensi Shearwall

$$
\text { Tebal : } 500 \mathrm{~mm}
$$

- Dimensi Balok Tepi

Tabel 5.

Rekapitulasi Dimensi Balok Tepi

\begin{tabular}{ccccccc}
\hline \multirow{2}{*}{ No } & \multirow{2}{*}{ Bentang } & Arah & h min & b min & \multicolumn{2}{c}{ Dimensi } \\
\cline { 6 - 7 } & & & & & h & b \\
\hline 1 & 10200 & Memanjang & 619,3 & 412,9 & 650 & 450 \\
2 & 9150 & Melintang & 555,5 & 370,4 & 650 & 450 \\
3 & 10700 & Memanjang & 649,6 & 433,1 & 650 & 450
\end{tabular}

\begin{tabular}{lllllll}
4 & 9150 & Melintang & 555,5 & 370,4 & 650 & 450 \\
5 & 8000 & Melintang & 485,7 & 323,8 & 650 & 450 \\
6 & 6000 & Melintang & 364,3 & 242,9 & 650 & 450 \\
7 & 7950 & Melintang & 482,7 & 321,8 & 650 & 450 \\
\hline \hline
\end{tabular}

\section{E. Perencanaan Struktur Primer}

Struktur utama adalah elemen utama suatu gedung dan berfungsi untuk menahan pembebanan yang berasal dari beban gravitasi dan beban lateral berupa beban gempa maupun beban angin. Elemen utama terdiri dari pelat, balok tepi, kolom dan shear wall. Perancangan elemen-elemen tersebut mengacu pada SNI-2847-2013[6].

1) Desain Pelat

\begin{tabular}{|c|c|c|c|}
\hline Arah Penulangan & Posisi Tulangan & & Penulangan \\
\hline \multirow[t]{8}{*}{ Arah X } & \multirow[t]{2}{*}{ Tumpuan Coloumn Strip } & Tarik & D $22-100 \mathrm{~mm}$ \\
\hline & & Tekan & D $22-200 \mathrm{~mm}$ \\
\hline & \multirow{2}{*}{$\begin{array}{l}\text { Lapangan Coloumn } \\
\text { Strip }\end{array}$} & Tarik & D $13-150 \mathrm{~mm}$ \\
\hline & & Tekan & D $13-300 \mathrm{~mm}$ \\
\hline & \multirow[t]{2}{*}{ Tumpuan Middle Strip } & Tarik & D $13-100 \mathrm{~mm}$ \\
\hline & & Tekan & D $13-200 \mathrm{~mm}$ \\
\hline & \multirow[t]{2}{*}{ Lapangan Middle Strip } & Tarik & D $13-150 \mathrm{~mm}$ \\
\hline & & Tekan & D $13-300 \mathrm{~mm}$ \\
\hline \multirow[t]{8}{*}{ Arah Y } & \multirow[t]{2}{*}{ Tumpuan Coloumn Strip } & Tarik & D $22-90 \mathrm{~mm}$ \\
\hline & & Tekan & D $22-150 \mathrm{~mm}$ \\
\hline & \multirow{2}{*}{$\begin{array}{l}\text { Lapangan Coloumn } \\
\text { Strip }\end{array}$} & Tarik & D $13-200 \mathrm{~mm}$ \\
\hline & & Tekan & D $13-400 \mathrm{~mm}$ \\
\hline & \multirow[t]{2}{*}{ Tumpuan Middle Strip } & Tarik & D $13-200 \mathrm{~mm}$ \\
\hline & & Tekan & D $13-400 \mathrm{~mm}$ \\
\hline & \multirow[t]{2}{*}{ Lapangan Middle Strip } & Tarik & D $13-200 \mathrm{~mm}$ \\
\hline & & Tekan & D $13-400 \mathrm{~mm}$ \\
\hline
\end{tabular}

Tabel 6.

Rekapitulasi Penulangan Pelat Option 1

\begin{tabular}{|c|c|c|c|}
\hline Arah Penulangan & \multicolumn{2}{|l|}{ Posisi Tulangan } & Penulangan \\
\hline \multirow[t]{8}{*}{ Arah X } & \multirow[t]{2}{*}{ Tumpuan Coloumn Strip } & Tarik & D $19-100 \mathrm{~mm}$ \\
\hline & & Tekan & D $19-150 \mathrm{~mm}$ \\
\hline & \multirow{2}{*}{$\begin{array}{l}\text { Lapangan Coloumn } \\
\text { Strip }\end{array}$} & Tarik & D $13-100 \mathrm{~mm}$ \\
\hline & & Tekan & D $13-200 \mathrm{~mm}$ \\
\hline & \multirow[t]{2}{*}{ Tumpuan Middle Strip } & Tarik & D $13-100 \mathrm{~mm}$ \\
\hline & & Tekan & D $13-200 \mathrm{~mm}$ \\
\hline & \multirow[t]{2}{*}{ Lapangan Middle Strip } & Tarik & D $13-150 \mathrm{~mm}$ \\
\hline & & Tekan & D $13-300 \mathrm{~mm}$ \\
\hline \multirow[t]{8}{*}{ Arah Y } & \multirow[t]{2}{*}{ Tumpuan Coloumn Strip } & Tarik & D $19-75 \mathrm{~mm}$ \\
\hline & & Tekan & D $19-150 \mathrm{~mm}$ \\
\hline & \multirow{2}{*}{$\begin{array}{l}\text { Lapangan Coloumn } \\
\text { Strip }\end{array}$} & Tarik & D $13-120 \mathrm{~mm}$ \\
\hline & & Tekan & D $13-250 \mathrm{~mm}$ \\
\hline & \multirow[t]{2}{*}{ Tumpuan Middle Strip } & Tarik & D $13-100 \mathrm{~mm}$ \\
\hline & & Tekan & D $13-200 \mathrm{~mm}$ \\
\hline & \multirow[t]{2}{*}{ Lapangan Middle Strip } & Tarik & D $13-150 \mathrm{~mm}$ \\
\hline & & Tekan & D $13-300 \mathrm{~mm}$ \\
\hline
\end{tabular}

Tabel 7.

Rekapitulasi Penulangan Pelat Option 2

2) Analisa Harga Besi Tulangan dan Beton Cor pada Pelat $t=250 \mathrm{~mm}$ dan $t=350 \mathrm{~mm}$

Dalam analisa perbandingan penulangan tebal pelat didapatkan kebutuhan tulangan untuk masing - masing ketebalan pelat yang berbeda. Setelah didapatkan kebutuhan tulangan pada masing - masing ketebalan pelat, maka selajutnya dilakukan analisa harga dari besi tulangan dan beton cor yang diperlukan. Pada perhitungan berikut ini akan diambil sampel contoh salah satu pelat ukuran $10200 \mathrm{~mm} \mathrm{x}$ $6000 \mathrm{~mm}$. 
Tabel 8.

Analisa Harga $\mathrm{t}=350 \mathrm{~mm}$

\begin{tabular}{ccc}
\hline \hline Material & Harga Satuan & Harga \\
\hline Besi & 340160,040 & Rp57.146.887 \\
Beton & 1314524,85 & Rp17.407.000 \\
& Total Harga & Rp74.553.887 \\
\hline \hline
\end{tabular}

Tabel 9.

Analisa Harga $\mathrm{t}=250 \mathrm{~mm}$

\begin{tabular}{ccc}
\hline \hline Material & Harga Satuan & Harga \\
\hline Besi & 253714,41 & Rp47.444.595 \\
\multirow{2}{*}{ Beton } & 1314524,85 & Rp19.055.000 \\
& Total Harga & Rp66.499.595 \\
\hline \hline
\end{tabular}

Perbandingan harga $=\frac{\text { Rp74.553.887-Rp66.499.595 }}{\text { Rp74.553.887 }} \times 100 \%$

$$
=10,803 \%
$$

Berdasarkan perhitungan analisa harga dapat disimpulkan bahwa dengan menggunakan alternatif Option 2 dapat menghemat biaya pembuatan pelat dengan presentase sebesar $10,803 \%$.

Tabel 10.

Rekapitulasi Penulangan Drop Panel

\begin{tabular}{ccc}
\hline \hline \multicolumn{2}{c}{ Posisi Tulangan } & Penulangan \\
\hline \multirow{2}{*}{ Lapangan } & Tarik & D 22-300 mm \\
& Tekan & D 22 $-450 \mathrm{~mm}$ \\
\multirow{3}{*}{ Tumpuan } & Tarik & D 22-100 mm \\
& Tekan & D 22-300 mm \\
\hline \hline
\end{tabular}

Tabel 11.

Rekapitulasi Penulangan Balok Tepi

\begin{tabular}{|c|c|c|c|c|c|c|c|}
\hline Letak & \multicolumn{4}{|c|}{ Tumpuan } & \multicolumn{3}{|c|}{ Lapangan } \\
\hline Atas & 9 D22 & \multicolumn{3}{|c|}{$\mathrm{As}=3422,57 \mathrm{~mm}^{2}$} & 2 D22 & \multicolumn{2}{|c|}{$\mathrm{As}=760,571 \mathrm{~mm}^{2}$} \\
\hline Bawah & $5 \mathrm{D} 22$ & \multicolumn{3}{|c|}{ As $=1901,43 \mathrm{~mm}^{2}$} & $4 \mathrm{D} 22$ & \multicolumn{2}{|c|}{ As $=1521,14 \mathrm{~mm}^{2}$} \\
\hline \multicolumn{8}{|c|}{$\begin{array}{c}\text { Tabel } 12 . \\
\text { Rekapitulasi Penulangan Kolom } \\
\end{array}$} \\
\hline \multicolumn{4}{|c|}{ Kolom } & \multirow{2}{*}{$\begin{array}{c}0,01 \mathrm{Ag} \\
\left(\mathrm{mm}^{2}\right)\end{array}$} & \multirow{2}{*}{$\begin{array}{c}0,06 \mathrm{Ag} \\
\left(\mathrm{mm}^{2}\right)\end{array}$} & \multirow{2}{*}{$\begin{array}{c}\text { Tul } \\
\text { pakai }\end{array}$} & \multirow{2}{*}{$\begin{array}{l}\text { Ag tul } \\
\left(\mathrm{mm}^{2}\right)\end{array}$} \\
\hline Let & & Din & lensi & & & & \\
\hline \multicolumn{2}{|c|}{$\begin{array}{l}\text { Groundfloor - } \\
\text { Lt } 3\end{array}$} & 1200 & 1200 & 14400 & 86400 & 28 D32 & 22528,0 \\
\hline \multicolumn{2}{|c|}{ Lantai $4-8$} & 1000 & 1000 & 10000 & 60000 & 24 D29 & 15858,9 \\
\hline \multicolumn{2}{|c|}{ Lantai $9-13$} & 800 & 800 & 6400 & 38400 & 20 D 25 & 9821,4 \\
\hline \multicolumn{2}{|c|}{ Lantai 14 - Atap } & 600 & 600 & 3600 & 21600 & 16 D22 & 6084,6 \\
\hline
\end{tabular}

Tabel 13.

Rekapitulasi Penulangan Shearwall

\begin{tabular}{ccc}
\hline \hline Tipe & $\begin{array}{c}\text { Tulangan Geser Vertikal } \\
\text { dan Horizontal }\end{array}$ & $\begin{array}{c}\text { Panjang Boundary } \\
\text { Element }\end{array}$ \\
\hline Arah Y & D $16-150$ & $2400 \mathrm{~mm}$ \\
Arah X & D $16-150$ & $1300 \mathrm{~mm}$ \\
\hline \hline
\end{tabular}

\section{F. Perencanaan Pondasi}

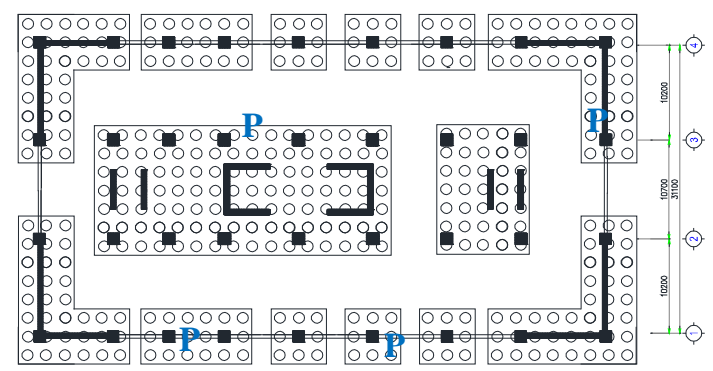

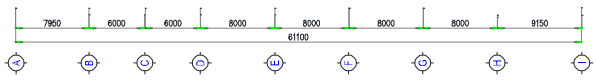

Gambar 6. Denah Perencanaan Pondasi

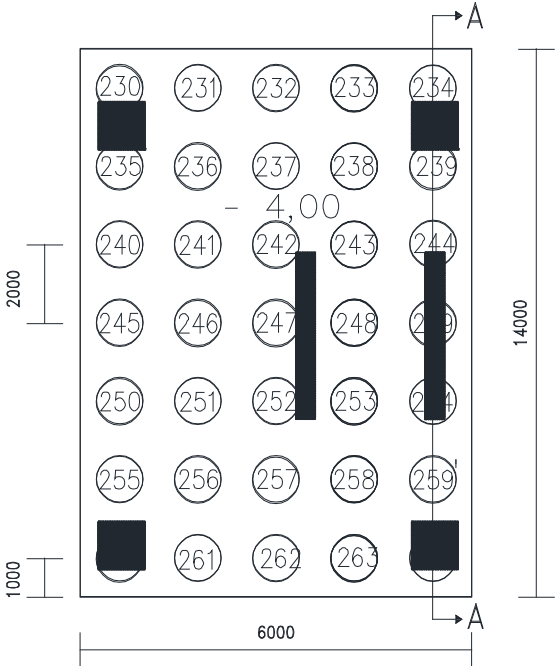

Gambar 7. Grup Tiang Pancang 1

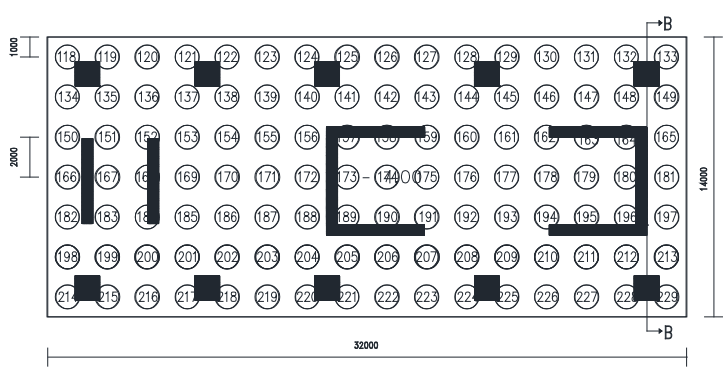

Gambar 8. Grup Tiang Pancang 2

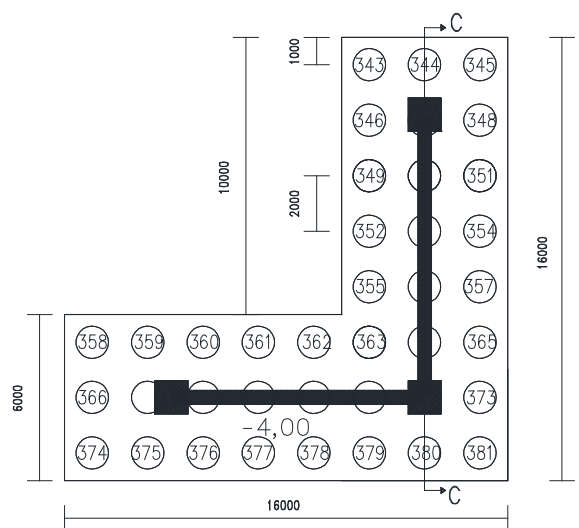

Gambar 9. Grup Tiang Pancang 3
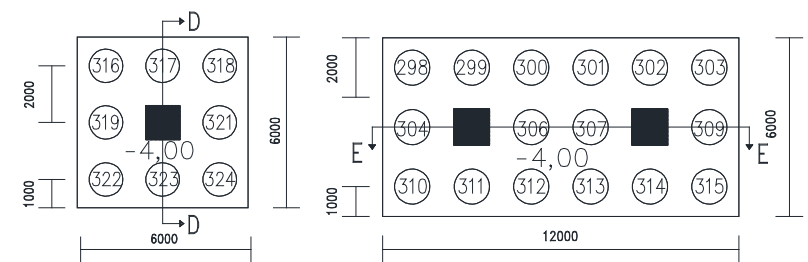

Gambar 10. Grup Tiang Pancang 4 dan 5

Tiang pancang yang akan digunakan merupakan tiang pancang jenis Prestressed Concrete Spun Piles produksi PT WIKA Beton dengan spesifikasi sebagai berikut.

- Outside diameter (D1) $\quad=60 \mathrm{~cm}$

- Inside Diameter (D2) $\quad=40 \mathrm{~cm}$

- Wall thickness $\quad=10 \mathrm{~cm}$

- Class = C

- Concrete cross section $\quad=1570,8 \mathrm{~cm}^{2}$

- Bending moment crack $=29$ ton.m

- Bending momen ultimate $=58$ ton.m

- Allowable axial load $\quad=229,5$ ton

- Concrete Strength $\quad=52 \mathrm{MPa}$ 


\section{KESIMPULAN DAN SARAN}

A. Kesimpulan

1. Analisa struktur menggunakan program bantu ETABS.

2. Studi Desain menggunakan sistem Flat Slab dengan membuat variasi terhadap tebal pelat menunjukan bahwa biaya pembuatan Option 1 ( $\mathrm{t}$ pelat $=350 \mathrm{~mm}$, t drop panel $=100 \mathrm{~mm}$ ) menghasilkan harga pembuatan sebesar Rp74.553.887 dan biaya pembuatan Option 2 (t pelat=250 $\mathrm{mm}$, t drop panel $=200 \mathrm{~mm}$ ) menghasilkan harga pembuatan sebesar Rp66.499.595. Sehingga dalam pembuatannya Option 2 dapat menghemat biaya pembuatan pelat sebesar $10,803 \%$.

3. Penggunaan sistem Flat Slab efisien terhadap waktu dalam pelaksanaannya karena tidak memerlukan bekisting balok dan tulangan pelat dapat menggunakan tulangan fabrikasi.

4. Perhitungan gaya gempa pada Desain Gedung Apartement One East menggunakan analisa respon spektrum di daerah Surabaya, sesuai dengan peraturan SNI 1726:2012.

5. Desain struktur beton bertulang menggunakan peraturan SNI 2847:2013, dengan sistem gedung yang digunakan adalah Sistem Rangka Gedung.

6. Pondasi direncanakan dengan pondasi dalam tiang pancang sesuai dengan ketentuan yang berlaku dan menerima beban melalui poer.

7. Hasil analisa struktur telah dilakukan pada Desain Apartement One East dituangkan pada gambar teknik pada lampiran.

\section{B. Saran}

1. Desain gedung yang dilakukan harus pada zona gempa yang sebenarnya agar ketepatan perhitungan dalam Desain lebih efisien dan efektif.

2. Data tanah yang dimiliki sebaiknya harus ada di setiap titik dari tiang pancang agar Desain bisa lebih efektif.

3. Pada Desain bangunan harus dipikirkan kemudahan dalam aplikasi di lapangan sehingga pelaksanaan dapat berjalan dengan baik, lancar, dan sesuai dengan Desain.

4. Pengembangan pada teknologi beton pratekan perlu dilakukan peningkatan, agar lebih mudah dalam pengerjaannya, dikarenakan penggunaan pratekan dapat membuat fungsi ruang pada gedung semakin efisien.

\section{DAFTAR PUSTAKA}

[1] Mohana HS and Kavan MR, "Comparative study of Flat Slab and Conventional Slab Structure Using ETABS for Different Earthquake Zones of India,” Int. Res. J. Eng. Technol., vol. 2, no. 3, pp. 19311936, 2015.

[2] R. C. Dhanaji, D. D. Mohite, C. P. Pise, Y. P. Pawar, S. S. Kadam, and C. M. Deshmukh, "Behaviour of multi-storied flat slab building considering shear walls: A review," Int. J. Eng. Res. Appl. www.ijera.com, vol. 6, no. 2, pp. 10-14, 2016.

[3] Direktorat Penyelidikan Masalah Bangunan, "Peraturan Pembebanan Indonesia Untuk Gedung (PPIUG),” Bandung, 1983.

[4] Badan Standarisasi Nasional, "SNI 1727:2013 Beban minimum untuk perancangan bangunan gedung dan struktur lain,” Jakarta, 2013.

[5] Badan Standardisasi Nasional, SNI 1726:2012 Tata cara perencanaan ketahanan gempa untuk struktur bangunan gedung dan non gedung. Jakarta: Badan Standardisasi Nasional, 2012.

[6] Badan Standardisasi Nasional, "SNI 2847-2013 : Persyaratan beton struktural untuk bangunan gedung,” Jakarta, 2013. 